\title{
Task Scheduling Algorithms in Cloud Computing: A Review
}

\author{
Ibrahim Mahmood Ibrahim \\ Duhok Polytechnic University, \\ Duhok, Kurdistan Region, Iraq. \\ ibrahim.mahmmod@dpu.edu.krd
}

A. H. Radie

The Islamic University

Najaf, Iraq

a.hussienradie@gmail.com

\author{
Karwan Jacksi \\ University of Zakho, \\ Duhok, Kurdistan Region, Iraq. \\ karwan.jacksi@uoz.edu.krd
}

\author{
Subhi R. M. Zeebaree \\ Duhok Polytechnic University, \\ Duhok, Kurdistan Region, Iraq. \\ subhi.rafeeq@dpu.edu.krd
}

\author{
Hanan M. Shukur \\ Al-Kitab University, \\ Kirkuk - Iraq. \\ hanan.m.shukur@uoalkitab.edu.iq
}

\author{
Zryan Najat Rashid \\ Sulaimani Polytechnic University, \\ sulaimani, Kurdistan Region, Iraq. \\ zryan.rashid@spu.edu.iq
}

\begin{abstract}
Mohammed A. M.Sadeeq
Duhok Polytechnic University, Duhok, Kurdistan Region, Iraq. mohammed.abdulrazaq@dpu.edu.krd
\end{abstract}

\author{
Hajar Maseeh Yasin \\ Duhok Polytechnic University, \\ Duhok, Kurdistan Region, Iraq. \\ hajar.yaseen@dpu.edu.krd
}

Article History: Received:11 January 2021; Accepted: 27 February 2021; Published online: 5 April 2021

\begin{abstract}
Cloud computing is the requirement based on clients and provides many resources that aim to share it as a service through the internet. For optimal use, Cloud computing resources such as storage, application, and other services need managing and scheduling these services. The principal idea behind the scheduling is to minimize loss time, workload, and maximize throughput. So, the scheduling task is essential to achieve accuracy and correctness on task completion. This paper gives an idea about various task scheduling algorithms in the cloud computing environment used by researchers. Finally, many authors applied different parameters like completion time, throughput, and cost to evaluate the system.
\end{abstract}

Keyword: Cloud Computing, Cloud Services, Task Scheduling.

\section{Introduction}

Cloud computing is a distributed computing system that offers software, CPU, memory, storage, and other computing resources. It provides on-demand services as a pay-per-use service through the internet. Cloud computing is used to construct and operate the cloud computing environments of virtualizing technologies (Anushree B, 2018; Manju Arora, 2020; Rashid et al., 2018). It allows sharing a single application or physical resource among multiple clients, and load balancing can be handled by virtualization (Hanan M. Shukur, 2020; Rashid et al., 2019). The IT Cloud computing model mainly focuses on the ease and speed of assigning IT resources, freeing end-users from IT infrastructure and location problems(Zeebaree et al., 2015). All of this is presented in a pay-as-you-go manner (Gibet Tani Hicham, 2016; Haji, Zeebaree, et al., 2020; M. A. Sadeeq et al., 2018). Cloud environments provide service providers and internet providers. The service provider is responsible for the software, network, and facilities used to create the service. Simultaneously, internet providers are also called customers or consumers of the Cloud (Abdulazeez et al., 2018; C. Thirumalaiselvan, 2017).

Cloud Operating Systems (COS) are commonly used with individual and business customers due to cloud technology's rapid growth (Zebari et al., 2011). The COS is an operating system on the server that deploys application software. Users do not have to install and link the app through a Web browser from the personal computer (Shukur, Zeebaree, Zebari, Zeebaree, et al., 2020). The cloud provider is responsible for storing and handling cloud storage data, protecting, upgrading the software, minimizing the costs of using the software, and effectively enhancing user experience (Alam, 2020; Salih et al., 2020; Zhen Du, 2017).

The task scheduling algorithm allocates user tasks to the cloud resources to maximize usage rate, reduce the make span, and balance the cloud infrastructure to avoid activities from being overburdened (Fahd Alhaidari, 2019; Iqbal, 2019; Safwat A. Hamad, 2016; Xiaozhong Geng, 2019). The scheduling could be either static or dynamic. In 
static planning, the scheduler identifies the specifics of the resources and tasks (S. Zeebaree et al., 2020). While in dynamic scheduling, the details of tasks and resources are undefined from the beginning (Sallow, Sadeeq, et al.). The scheduler makes dynamic scheduling plans to select appropriate resources for user activities (A. M. Senthil Kumar, 2018; Dinkan Patel 2018; Kadda Beghdad Bey, 2019). The significant elements in cloud technology are resource providers, task/service schedules, and clients. Scheduling can be defined as the period a resource is allocated to a request. The responsibility of scheduling algorithms is allocating resources to task requests in the Cloud (Arghavan Keivani 2018; S. R. Zeebaree et al., 2020).

The rest of our paper is structured as follows. Section $\mathbf{2}$ introduces cloud types and services. Section 3 provides cloud scheduling. Section 4 presents a literature review related to the scheduling algorithm, Comparison and Discussion are provided in Section $\mathbf{5}$, and the conclusion is in Section $\mathbf{6}$.

\section{Cloud Types and Services}

The Cloud model can be analyzed from an organizational view into different types and can be distinction depend on the extent to which the user's and providers' organizational units are separated from each other (Z. Ageed et al., 2020; Haji, Ahmad, et al., 2020). Cloud models can be classified as illustrated in Figure 1.

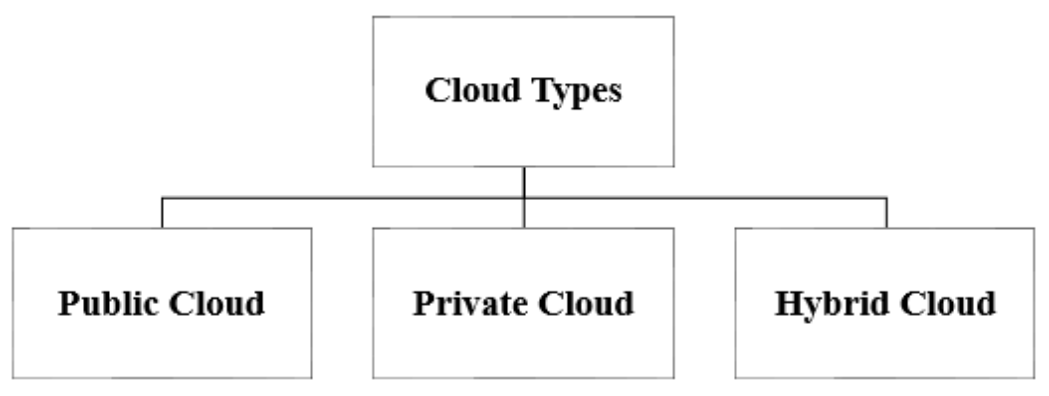

Figure 1: Types of Cloud

Public clouds: enables users to use the Cloud through web browser interfaces. Users need to pay-per-use services or resources (Aaqib Rashid, 2019). The public Cloud is available by some companies like google, amazon Microsoft. Private clouds: this type of Cloud resides inside the organization for its internal use to exclusively support its business operations. More protection is controlled by the private cloud than a public cloud (Shukur, Zeebaree, Zebari, Ahmed, et al., 2020). Many medical offices, banking, and other organizations use private Cloud to store their data on this type of Cloud (Abdulla et al., 2020; Z. S. Ageed et al., 2020). Hybrid Cloud: in this type, the services distribute between private and public, where critical applications are stored within the network of the organization, and other services could be stored outside the network of the organization (Christian Baun, 2011; Laffly, 2020; Pradeep Krishnadoss, 2018; Waleed Abd Elkhalik, 2018). Cloud infrastructure offers three distinct service models that meet a number of market criteria. Figure 2 below shows both services:

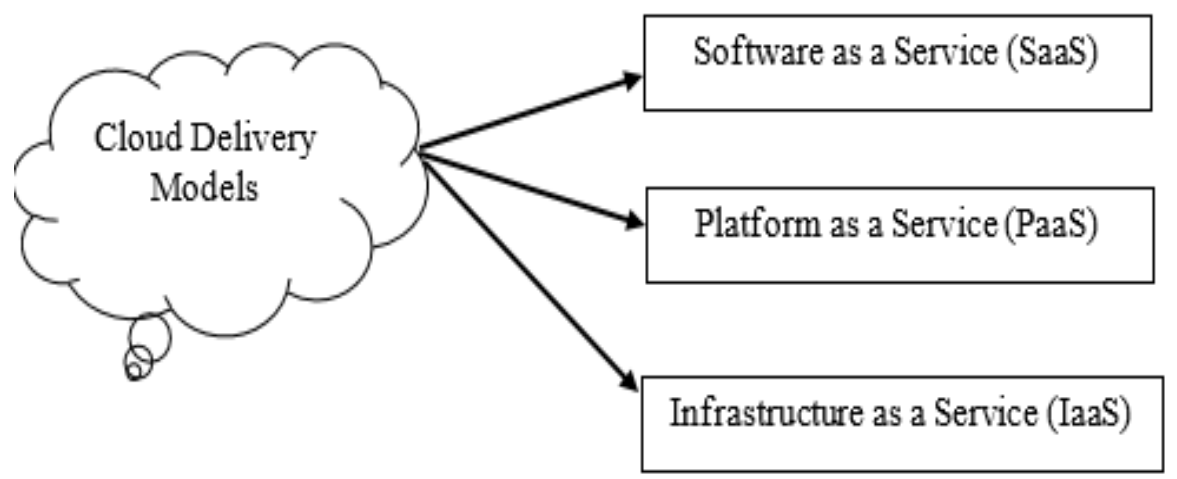

Figure 2: Cloud Services 
Saas provides user friendly applications through a web browser or via specific services based on the cloud. For example, Google Docs, Gmail, and Google Talk are the most popular providers (Abdulraheem et al., 2020; Dino et al., 2020; Laith Abualigah, 2020; Omar M. Ahmed, 2020). PaaS provides different computing services to the user for implementation, execution, testing, and hosting application or program. Different services come under this model: a database for storing data and an operating system to provide the execution environment (M. Sadeeq et al., 2020). Google App Platform and Microsoft Azure Platform are the most common providers. IaaS allows the user, through virtual machines, to access the underlying infrastructure, giving the user more flexibility than PaaS. It helps the user to find out its required infrastructure through the internet (Yazdeen et al., 2021). The most common examples are Amazon Cloud and Elastic Compute Cloud (EC2) (Abdullah et al., 2020; Ahmed Meri Kadhum, 2017; Ram Shringar Rao, 2021).

\section{Cloud Scheduling}

The concept of cloud scheduling refers to the technology for mapping jobs to a range of virtual machines or assigning virtual machines to use the resources available to fulfill user requirements (Sallow, Zeebaree, et al.; Shukur, Zeebaree, Ahmed, et al., 2020). The purpose of using scheduling methods in cloud computing is to enhance system throughput and load balancing, reduce costs, increase resource utilization, save energy, and reduce processing time (Hasan et al., 2021). Scheduling manages CPU and memory availability; a good scheduling plan increases resource utilization (D.I. George Amalarethinam, 2017; Nora Almezeini, 2018; Sharif et al., 2020). Scheduling can be classified into jobs and task scheduling. Most of the job scheduling techniques are present in a computing system are appropriate enough to be used in the cloud system (Rashid et al.). The benefit of using job scheduling algorithms is to obtain the best performance and maximum system throughput (Sulaiman et al., 2020). Job scheduling can be classified into the following group of algorithms: Batch Mode Heuristic Scheduling Algorithms (BMHA), Online Mode Heuristic Algorithms, Dependency mode heuristic Algorithm (Pratisha Sarma, 2017).

While the task scheduling techniques are used to find the order in which tasks or activities should be completed. It focuses on mapping the user tasks to the available resources. The backbone for efficient task scheduling is virtualization (Jghef et al., 2020). Nevertheless, its performance could affect the performance of the cloud environment. Beast scheduling methods minimize the total time completion of the task, improve device load balancing, and improve resource usage (Mohammed et al., 2021). Task scheduling can be classified into the following group of scheduling algorithms: static, dynamic, workflow, cloud service, real-time, Heuristic, and opportunistic load balancing (OLB) scheduling algorithms (Amandeep Kaur, 2018; Yanyue Yu, 2019). Users have sent their tasks to the Cloud, and they must allocate them to the processor. It is now a question of how processor tasks are allocated such that the cloud owner earns the least time and maximum benefit (M. M. Sadeeq et al., 2021). The work programming fixes the problem that tasks are assigned to the processor that takes account of the other factor. Figure 3 shows the cloud system schedule of a mission (Kalka Dubeya, 2017):

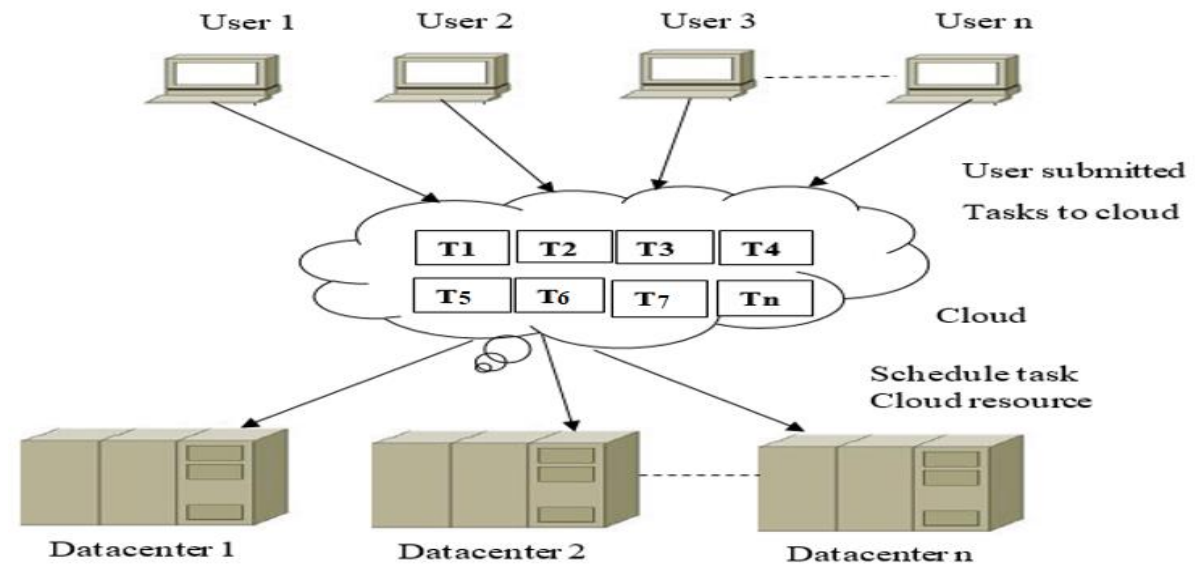

Figure 3: Task Scheduling 


\section{Literature Review}

In 2016, Zhifeng Zhong, and et al. (Zhifeng Zhong, 2016), introduced a Greedy Particle Swarm Optimization (G\&PSO) approach to resolve task scheduling. The findings indicate that the suggested algorithm improved each virtual machine's performance, such as well local and global search abilities, a faster convergence rate, and a more balanced workload. Hence the Greedy Particle Swarm Optimization outperforms the classical PSO in terms of maximize utilization of resources.

In 2016, WANG Bei and Li Jun (WANG Bei, 2016), considered a Multi-Population Genetic Algorithm (MPGA) for load balancing, is applied to solve task problems in the cloud system prevent premature convergence. In this work, several methods depend on which min-min and max-min approaches have been used to initialize the population. Then the metropolis criterion is applied to screen the offspring where the flawed individual could be admitted. Then the population diversity can be preserved, and it is even possible to prevent the optimum local. The obtained results showed that the MPGA could achieve good task scheduling results, such as minimize cost and execution time.

In 2016, Ruonan Lin and Qiang Li (Ruonan Lin, 2016), A pre-allocation Ant Colony Optimization (PACO) method was suggested for task scheduling in the cloud system. This algorithm incorporates the improved Ant Colony Optimization (ACO) algorithm and the template size to individual schedule tasks. The proposed algorithm has good efficiency inside the simulated software. The experiments demonstrate that the PACO Scheduling productivity will enhance the task.

In 2017, Hu Yao et al. (Hu Yao, 2017) described a "three-stage selection method," and the genetic approach of "total-division-total" is put forward to enhance genetic strategy. The obtained results from the CloudSim tool indicate that the enhanced algorithm outperforms a simple genetic algorithm (SGA) in the term task completion time. It is a robust algorithm for cloud computing task scheduling.

In 2017, Ashish Gupta and Ritu Garg (Ashish Gupta, 2017), a meta-heuristic method of the ant colony optimization algorithm was suggested to resolve task scheduling in the cloud system focusing primarily on two targets, i.e., reducing makespan/computation time and optimizing load balancing. The study results indicate that the suggested load balancing ant colony optimization algorithm (LB-ACO) produces better results than the NSGA-II algorithm in the makespan and balancing load.

In 2017, Xing Jia Wei and et al. [41] proposed a Simulated Annealing Multi-Population Genetic Algorithm (SAMPGA) algorithm to resolve the scheduling issue. To prevent the local optimum and enhance the optimum global efficiency, SA is inserted into SAMPGA. Simultaneously, a family evolution method based on the adaptive mechanism in MPGA is suggested to find a suitable solution and enhance convergence speed. The simulated result illustrates that the SAMPGA has a good result for enhancing the task's completion time, cost, and balance load.

In 2017, Jaspnder Kaur and Brahmalen Kaur Sidhu (Sidhu, 2017), a new algorithm for task scheduling using the Flower Pollination Algorithm (TSFPA) was implemented to assign resources the task. The algorithm aims to decrease the task execution time (makespan). The efficiency of the suggested method (TSFPA) was compared with many other approaches such as genetic algorithm (GA), First Come First Serve (FCFS), and Round Robin (RR) scheduling approach, the result of the suggested approaches is better than compared algorithm concerning makespan.

In 2017, Danlami Gabi and et al. (Danlami Gabi, 2017), a Multi-Objective QoS approach was presented to resolve customer expectations using execution time and cost parameters. In order to solve the model, Cloud Scalable Multi-Objective Cat Swarm Optimization (CSO) based Simulated Annealing (SA) (CSM-CSOSA) approaches were suggested. The Taguchi Orthogonal technique is applied to enhance the simulated annealing and incorporate the proposed algorithm into the local search to improve its exploration ability.

In 2018, N. Gopalakrishnan and C. Arun (N. GOBALAKRISHNAN, 2018) proposed a hybrid Genetic Gray Wolf Optimization Algorithm (GGWO) to resolve and improve the task scheduling issues. The obtained result indicates that the suggested method reduces computing time, the cost of migration, and load usage compared to QWO and GA algorithms. 
In 2018, Mehran Ashouraei and et al. (Mehran Ashouraei, 2018) presented the parallel genetic algorithm-based approach for scheduling tasks with priorities to use resources effectively and minimize resource waste in cloud systems. This method is carried out by increasing the load balance when selecting good resources for short-term arrival tasks in order to eliminate work failures.

In 2018, Fang Yiqiu and Li Xiaosheng (L. X. Fang Yiqiu, 2018), Introduced a real-time improvement ant colony algorithm for a virtual machine (VM-ACO). In order to finish the task's load balance, the method takes into consideration time. The findings demonstrate that the VM-ACO technique outperforms the ant colony algorithm in terms of resource state and polling, task latency, and time to accomplish the task and load balance.

In 2018, Shuang YIN (Shuang YIN, 2018), A new preparation algorithm was implemented that uses doublefitness algorithm-load balance and cost completion genetic algorithm (LCGA). The schedule ensures a balance of load which reduces the cost of completing the mission. The LCGA algorithm is comparable to the load-balancing genetic algorithm (LGA) and the task-complete cost genetic algorithm (CGA) reveals that a programming algorithm's performance and optimization approach is usable in the simulation experiment.

In 2019, Negar Chitgar and et al. (Negar Chitgar, 2019), a technique for scheduling workload based on the virtual machine grouping in the cloud system was implemented. The suggested approach aims to enhance the cloud environment's performance by decreasing make span and response time and maximizing virtual machines' usage. Using various performance metrics, the proposed algorithm is superior to other existing methods.

In 2019, Fang Yiqiu and et al. (X. X. Fang Yiqiu, Ge Junwei, 2019), Binary coded chromosomes for resource scheduling is suggested to be a strategy for premature optimization of the risk of cross-over mutation in adaptive genetic algorithms (AGA). The improved genetic algorithm (AGA) is compared to the standard genetic Algorithm (SGA). The findings of the CloudSim tool show that the improved approach has an effective planning algorithm.

In 2019 A.M.Senthil Kumar and et al. (A.M.Senthil Kumar, 2019) proposed successful hybrid task scheduling to reduce the overall execution time using Genetic Algorithm (GA) and Particle Swarm Optimization (PSO) algorithms. PSO helped GA achieve better results in the hybrid Genetic Algorithm - Particle Swarm Optimization (GA-PSO algorithm compared to the standard genetic algorithm, Min-Min, and Max-Min algorithms.

In 2019, Ping Zhu et al. (Ping Zhu, 2019), a power-aware and real-time scheduling (PRTS) algorithm were proposed to decrease workflow costs and reduce energy consumption. There are two components of the proposed algorithm: scheduling the most cost-effective virtual machines based on the critical path without missing the deadline, tracking the dynamic slack, and reclaiming them to implement the energy-saving DVFS technique.

In 2019, Abdullah Alzaqebah et al. (Abdullah Alzaqebah, 2019), This study used a Grey Wolf Optimization (GWO) algorithm with fitness function modifications by making it manage multi-objectives in single fitness; the makpane and cost are the targets used in fitness to resolve the issue of task scheduling. The primary aim of the proposed approach is to minimize both cost and makespan. The obtained results from the CloudSim tool indicate that the proposed MGWO algorithm outperforms both the traditional GWO algorithm and Whale Optimization Algorithm (WOA) in terms of cost, make space.

In 2019, Abdulsalam Alsmady et al. (Abdulsalam Alsmady, 2019) a Memetic Algorithm (MA) was proposed to solve cloud workflow-scheduling, considering cost and time as two goals to optimize the scheduling of scientific workflows in a cloud system. As an additional operator for the Genetic Algorithm (G.A.), the (MA) algorithm used the local search algorithm for the hill climbing to improve individual solutions during a global search.

In 2019, Shengmei Liu and Yari Yin (Shengmei Liu, 2019) improved discrete particle swarm optimization algorithm (IDPSO) used a sinusoidal strategy-based dynamic inertia weight optimization approach to make particles adaptive to various phases in a search for the optimal global solution. The results show that the IDPSO approach outperforms the DPSO and FCFS algorithm based on completion time and convergence.

In 2019, SHAN CHEN PANG et al. (SHANCHEN PANG 2019) An efficient hybrid algorithm proposed for Distribution Estimation Algorithm and genetic algorithm (EDA-GA) to resolve the issue of multi-objective task scheduling with the target of minimizing the execution time of the task and enhancing the ability to balance the load of the environment. The suggested method first uses EDA operations to create some suitable solution, then uses a genetic algorithm to produce new solutions depend on the optimal solution chosen in the previous stage to extend a 
search scope of solutions. The findings results indicate that the proposed algorithm has excellent convergence speed and search capability.

In 2019, Raja Masadeh et al. (Raja Masadeh, 2019) proposed the algorithm's vocalization for humpback whale optimization (VWOA). The VWOA mimics humpback whales' vocalization behavior, and in a cloud system, it is used to optimize task scheduling. A suggested multi-objective model is the basis of the VWOA scheduler. It reduces completion time, cost, and energy usage and maximizes the use of resources. The experiment results on the test data showed that the VWOA scheduler has better performance in terms of cost, makespan, and the degree of imbalance, resource utilization, and energy consumption than the results of the standard whale optimization algorithm (WOA) and round-robin (RR) algorithm.

In 2020, Yong Shi and et al. (Yong Shi, 2020) proposed a BMin algorithm to enhance the Min-min algorithm's efficiency. A cloudsim simulation program evaluates the proposed algorithm, and the result indicates that the suggested algorithm reduces completion time, maximizes throughput, and enhances the load balance among resources.

In 2020, Sanj M S et al. (Sanaj M S, 2020) suggested an improved Round Robin (ERR) technique to increase efficiency without influencing classical RR functionality. The CloudSim toolkit applies and tests the proposed algorithm. The results indicate the total waiting time for the tasks in a specific number of cloudlets in ERR is minimized under the same conditions compared to classical RR.

In 2020, Vijayalakshmi A. Lepkshi et al. (Vijayalakshmi A. Lepaksh, 2020) proposed an Efficient Resource Allocation with Score (ERAS) for scheduling task in cloud environments, which considers Virtual Machines (VM) temporary operational availability by suggesting different types of delays and EFT to set the processor for scheduling tasks to a standardized score. The results obtained show that the ERAS algorithm's improved reliability provides better efficiency compared to current approaches that only regard EFT for allocations.

In 2020, Zhong Zong et al. (Zong, 2020) Suggest a combination of the methodology of dynamic fusion mission planning, genetic approach and ant-colony system. This limits the energy consumption of cloud computing data and storage facilities. The test results demonstrate that the suggested approach in the task programming would substantially minimize cloud computing device time and energy usage.

\section{Comparison and Discussion}

This paper aims to overview various algorithms proposed by researchers in the previous studies for scheduling tasks in cloud computing. There are many challenging schedule issues in cloud computing infrastructure like computation time, load balancing, resource utilization, cost, and QoS. According to their experiments, there are good results for many algorithms compared to another algorithm under the same condition. For example, the author in reference (Zhifeng Zhong, 2016) proposed an algorithm (G\&PSO), the obtained results show that it reduces the overall task completion time compared to the practical swarm optimization algorithm. While the author in reference (Ashish Gupta, 2017) suggested (LB-ACO) algorithm to minimize the make span and distribute the load in balance, the proposed algorithm results are better compared to the NSGA-II algorithm. Table 1 summarizes the previous study reviewed in this paper and related to task scheduling in cloud computing.

Table 1: Summary of reviewed papers related to the task scheduling in the cloud computing

\begin{tabular}{|l|l|l|l|l|l|}
\hline Ref. & Year & Applied Algorithm & Parameters & Finding & Tools \\
\hline (Zhifeng Zhong, 2016) & 2016 & $\begin{array}{l}\text { (G\&PSO) algorithm } \\
\text { completion time, } \\
\text { workload, resource } \\
\text { utilization }\end{array}$ & $\begin{array}{l}\text { Compared to the PSO algorithm, } \\
\text { it decreases the overall task time } \\
\text { completion and balances each } \\
\text { virtual machine's workload. }\end{array}$ & Clouds \\
\hline (WANG Bei, 2016) & 2016 & $\begin{array}{l}\text { Multi-Population } \\
\text { Genetic Algorithm } \\
\text { (MPGA.) }\end{array}$ & $\begin{array}{l}\text { Cost and time } \\
\text { consuming, load } \\
\text { balancing. }\end{array}$ & $\begin{array}{l}\text { Better performance in both } \\
\text { processing costs and time- } \\
\text { consuming than the TCGA and } \\
\text { SAGA algorithms balances the } \\
\text { load of the inter-nodes well. }\end{array}$ & Matlab \\
\hline (Ruonan Lin, 2016) & 2016 & PACO algorithm & Completion time & $\begin{array}{l}\text { PACO could enhance task } \\
\text { scheduling efficiency. Better } \\
\text { than min-min and genetic } \\
\text { algorithm for the completion of }\end{array}$ & Clouds \\
\hline
\end{tabular}


A. H. Radie, Hanan M. Shukur, Mohammed A. M.Sadeeq, Karwan Jacksi, Zryan Najat Rashid Hajar Maseeh Yasin, Subhi R. M. Zeebaree, Ibrahim Mahmood Ibrahim

\begin{tabular}{|c|c|c|c|c|c|}
\hline & & & & the task. & \\
\hline (Hu Yao, 2017) & 2017 & $\begin{array}{l}\text { IGA (Improvement } \\
\text { Genetic Algorithm) }\end{array}$ & $\begin{array}{l}\text { Task and } \\
\text { Completion Time }\end{array}$ & $\begin{array}{l}\text { Improve the performance of a } \\
\text { task scheduling compared to } \\
\text { SGA (Simple Genetic } \\
\text { algorithm) }\end{array}$ & CloudSim \\
\hline (Ashish Gupta, 2017) & 2017 & LB-ACO Algorithm & $\begin{array}{l}\text { load balancing, } \\
\text { makespan }\end{array}$ & $\begin{array}{l}\text { Better load balance and less } \\
\text { makespan compared with the } \\
\text { NSGA-II algorithm. }\end{array}$ & CloudSim \\
\hline (Xing Jia Wei, 2017) & 2017 & SAMPGA algorithm & $\begin{array}{l}\text { completion time, } \\
\text { cost, load } \\
\text { imbalance, } \\
\text { convergence speed }\end{array}$ & $\begin{array}{l}\text { In terms of cost, completion } \\
\text { time, convergence speed, and } \\
\text { load imbalance, SAMPGA } \\
\text { surpasses SAGA, MPGA, and } \\
\text { SA. }\end{array}$ & MATLAB \\
\hline (Sidhu, 2017) & 2017 & TSFPA algorithm & Makespan & $\begin{array}{l}\text { In terms of makespan, TSFPA } \\
\text { performance is higher than GA, } \\
\text { RR, and FCFS. }\end{array}$ & CloudSim \\
\hline (Danlami Gabi, 2017) & 2017 & $\begin{array}{l}\text { CSM-CSOSA } \\
\text { algorithm }\end{array}$ & $\begin{array}{l}\text { execution time, } \\
\text { execution cost, QoS }\end{array}$ & $\begin{array}{l}\text { The obtained findings are } \\
\text { compared with (MOGA), } \\
\text { (MOSACO), and (MOSACO) } \\
\text { (MOPSO), where the proposed } \\
\text { method is better performance } \\
\text { with improved QoS. }\end{array}$ & CloudSim \\
\hline $\begin{array}{l}\text { (N. } \\
\text { GOBALAKRISHNAN, } \\
\text { 2018) }\end{array}$ & 2018 & (GGWO.) Algorithm & $\begin{array}{l}\text { computation time, } \\
\text { cost, energy } \\
\text { consumption, load } \\
\text { utilization }\end{array}$ & $\begin{array}{l}\text { Compared to standard GWO and } \\
\text { GA, GGWO will improve task } \\
\text { scheduling. }\end{array}$ & CloudSim \\
\hline $\begin{array}{l}\text { (Mehran Ashouraei, } \\
\text { 2018) }\end{array}$ & 2018 & $\begin{array}{l}\text { parallel genetic } \\
\text { algorithm }\end{array}$ & $\begin{array}{l}\text { Load balancing, } \\
\text { energy usage, } \\
\text { migration rate, } \\
\text { resource utilization }\end{array}$ & $\begin{array}{l}\text { Enhance the load balance level } \\
\text { by selecting better tools to } \\
\text { execute the arrival tasks at the } \\
\text { lower task failure rate in a } \\
\text { shorter period. }\end{array}$ & Matlab \\
\hline $\begin{array}{l}\text { (L. X. Fang Yiqiu, } \\
\text { 2018) }\end{array}$ & 2018 & VM-ACO algorithm & $\begin{array}{l}\text { task transmission, } \\
\text { execution time, and } \\
\text { load balancing }\end{array}$ & $\begin{array}{l}\text { It performs better than the ant } \\
\text { colony algorithm in task latency, } \\
\text { time to finish the task, and load } \\
\text { balance. }\end{array}$ & CloudSim \\
\hline (Shuang YIN, 2018) & 2018 & LCGA algorithm & load balancing, cost & $\begin{array}{l}\text { The LCGA algorithm is } \\
\text { compared with LGA, CGA } \\
\text { methods, and the results } \\
\text { illustrate that the scheduling } \\
\text { algorithm is successful and the } \\
\text { optimization method is used. }\end{array}$ & CloudSim \\
\hline (Negar Chitgar, 2019) & 2019 & $\begin{array}{l}\text { A new method for } \\
\text { scheduling workload } \\
\text { based on VM } \\
\text { grouping }\end{array}$ & $\begin{array}{l}\text { Makespan time, } \\
\text { response time, } \\
\text { resource utilization }\end{array}$ & $\begin{array}{l}\text { The grouping algorithm for VMs } \\
\text { reduces the makespan time and } \\
\text { average response time. In } \\
\text { contrast with the SJF and Min- } \\
\text { Min algorithms, this increases } \\
\text { the resource utilization ratio. }\end{array}$ & CloudSim \\
\hline $\begin{array}{l}\text { (X. X. Fang Yiqiu, Ge } \\
\text { Junwei, 2019) }\end{array}$ & 2019 & $\begin{array}{l}\text { adaptive genetic } \\
\text { algorithm (AGA.) }\end{array}$ & $\begin{array}{l}\text { Completion time, } \\
\text { load balancing }\end{array}$ & $\begin{array}{l}\text { Good effect on resource } \\
\text { scheduling provides a more } \\
\text { reasonable and optimal task } \\
\text { scheduling result compared with } \\
\text { the adaptive (AGA) and (SGA) } \\
\text { algorithm }\end{array}$ & CloudSim \\
\hline (A.M.Senthil Kumar, & 2019 & (GA-PSO) algorithm & response time & The result of the hybrid GA- & CloudSim \\
\hline
\end{tabular}




\begin{tabular}{|c|c|c|c|c|c|}
\hline 2019) & & & & $\begin{array}{l}\text { PSO algorithm is better than } \\
\text { GA, Max-Min, and Min-Min. }\end{array}$ & \\
\hline (Ping Zhu, 2019) & 2019 & PRTS algorithm & Energy & $\begin{array}{l}\text { Up to } 12.3 \% \text { energy saving } \\
\text { compared to the base algorithm } \\
\text { ESS }\end{array}$ & LIGO \\
\hline $\begin{array}{l}\text { (Abdullah Alzaqebah, } \\
\text { 2019) }\end{array}$ & 2019 & MGWO algorithm & $\begin{array}{l}\text { Makespan, cost, } \\
\text { degree of imbalance }\end{array}$ & $\begin{array}{l}\text { MGWO has better performance } \\
\text { in terms of makeup, cost, and } \\
\text { degree of imbalance than } \\
\text { traditional Grey (GWO) and } \\
\text { (WOA) algorithms. }\end{array}$ & CloudSim \\
\hline $\begin{array}{l}\text { (Abdulsalam Alsmady, } \\
\text { 2019) }\end{array}$ & 2019 & MA algorithm & Makespan, cost & $\begin{array}{l}\text { The MA reduced makespan and } \\
\text { outperformed the algorithms of } \\
\text { GA and PSO. }\end{array}$ & CloudSim \\
\hline (Shengmei Liu, 2019) & 2019 & IDPSO algorithm & $\begin{array}{l}\text { Completion time, } \\
\text { converge }\end{array}$ & $\begin{array}{l}\text { IDPSO better than DPSO and } \\
\text { FIFO in terms of completion } \\
\text { time and converges }\end{array}$ & CloudSim \\
\hline $\begin{array}{l}\text { (SHANCHEN PANG } \\
\text { 2019) }\end{array}$ & 2019 & EDA-GA algorithm & $\begin{array}{l}\text { Convergence, } \\
\text { completion time, } \\
\text { load balancing }\end{array}$ & $\begin{array}{l}\text { EDA-GA algorithm has better } \\
\text { convergence, search capability, } \\
\text { minimizing task execution time, } \\
\text { and improving load balancing } \\
\text { capability. compared with EDA } \\
\text { and GA }\end{array}$ & CloudSim \\
\hline [56] & 2019 & VWOA algorithm & $\begin{array}{l}\text { makespan, cost, and } \\
\text { energy and resource } \\
\text { utilization }\end{array}$ & $\begin{array}{l}\text { In terms of makespan, } \\
\text { cost, degree of imbalance, } \\
\text { energy consumption, and } \\
\text { resource utilization, the } \\
\text { proposed algorithm improved } \\
\text { performance compared to WOA } \\
\text { and RR algorithms }\end{array}$ & CloudSim \\
\hline (Yong Shi, 2020) & 2020 & BMin algorithm & $\begin{array}{l}\text { completion time, } \\
\text { throughput, load } \\
\text { balancing }\end{array}$ & $\begin{array}{l}\text { Reduce time of completion, and } \\
\text { improved load balance compare } \\
\text { to Min-min }\end{array}$ & CloudSim \\
\hline (Sanaj M S, 2020) & 2020 & ERR algorithm & $\begin{array}{l}\text { Waiting time, } \\
\text { execution time, and } \\
\text { residue energy. }\end{array}$ & $\begin{array}{l}\text { Under the same conditions, the } \\
\text { overall waiting time for ERR } \\
\text { tasks decreased relative to RR. } \\
\text { The ERR algorithm surpasses } \\
\text { such algorithms as ACO, GA, } \\
\text { M.P.A., Min-Min, and PSO } \\
\text { regarding execution time and } \\
\text { residue energy. }\end{array}$ & CloudSim \\
\hline $\begin{array}{l}\text { (Vijayalakshmi A. } \\
\text { Lepaksh, 2020) }\end{array}$ & 2020 & ERAS algorithm & $\begin{array}{l}\text { makespan. } \\
\text { Reliability }\end{array}$ & $\begin{array}{l}\text { Compared to the EFT algorithm } \\
\text { for allocation, the ERAS } \\
\text { algorithm increases reliability } \\
\text { with better performance. }\end{array}$ & CloudSim \\
\hline (Zong, 2020) & 2020 & $\begin{array}{l}\text { combined GA and } \\
\text { ACA. }\end{array}$ & $\begin{array}{l}\text { Execution time, } \\
\text { energy }\end{array}$ & $\begin{array}{l}\text { The suggested method reduces } \\
\text { the time and total energy } \\
\text { consumption of tasks for cloud } \\
\text { system computing. }\end{array}$ & CloudSim \\
\hline
\end{tabular}

\section{Conclusion}

Cloud computing is a huge source, according to the requirement of customers, of computational power, storage, software and a number of other facilities. The key objective of the task in the cloud setting is the distribution of available resources to the task in an appropriate structure. The primary purpose of the programming is to maximize resource use and reduce the time consumption. A number of algorithms have been analyzed in this article. In most 
algorithms, the comparative analysis has been studied based on different dimensions, processes, conditions, results, and instruments.

\section{References}

7. A. M. Senthil Kumar, M. V. (2018). Task scheduling in a cloud computing environment using HGPSO algorithm. Published Online, Springer.

8. A.M.Senthil Kumar, K. P., Siva Shankar S. (2019). An efficient task scheduling in a cloud computing environment using hybrid Genetic Algorithm - Particle Swarm Optimization (GAPSO) algorithm. Paper presented at the International Conference on Intelligent Sustainable Systems (ICISS 2019).

9. Aaqib Rashid, A. C. (2019). Cloud Computing Characteristics and Services: A Brief Review. International Journal of Computer Sciences and Engineering, 7(2), 421-426.

10. Abdulazeez, A. M., Zeebaree, S. R., \& Sadeeq, M. A. (2018). Design and Implementation of Electronic Student Affairs System. Academic Journal of Nawroz University, 7(3), 66-73.

11. Abdulla, A. I., Abdulraheem, A. S., Salih, A. A., Sadeeq, M. A., Ahmed, A. J., Ferzor, B. M., et al. (2020). Internet of Things and Smart Home Security. Technol. Rep. Kansai Univ, 62(5), 2465-2476.

12. Abdullah Alzaqebah, R. A.-S., Raja Masadeh. (2019). Task Scheduling based on Modified Grey Wolf Optimizer in Cloud Computing Environment. IEEE.

13. Abdullah, P. Y., Zeebaree, S. R., Shukur, H. M., \& Jacksi, K. (2020). HRM system using cloud computing for Small and Medium Enterprises (SMEs). Technology Reports of Kansai University, 62(04), 04.

14. Abdulraheem, A. S., Salih, A. A., Abdulla, A. I., Sadeeq, M. A., Salim, N. O., Abdullah, H., et al. (2020). Home automation system based on IoT.

15. Abdulsalam Alsmady, T. A.-K., Wail Mardini, Hadeel Alazzam ,Yaser Khamayseh. (2019). Workflow Scheduling in Cloud Computing Using Memetic Algorithm. Paper presented at the Jordan International Joint Conference on Electrical Engineering and Information Technology (JEEIT), Jordan.

16. Ageed, Z., Mahmood, M. R., Sadeeq, M., Abdulrazzaq, M. B., \& Dino, H. (2020). Cloud computing resources impacts on heavy-load parallel processing approaches. IOSR Journal of Computer Engineering (IOSR-JCE), 22(3), 30-41.

17. Ageed, Z. S., Ibrahim, R. K., \& Sadeeq, M. A. (2020). Unified Ontology Implementation of Cloud Computing for Distributed Systems. Current Journal of Applied Science and Technology, 82-97.

18. Ahmed Meri Kadhum, M. K. H. (2017). Assessing the Determinants of Cloud Computing Services for Utilizing Health Information Systems: A Case Study. International Journal on advanced Science Engineering information technology, 7, 503-510.

19. Alam, T. (2020). Cloud Computing and its role in the Information Technology. IAIC Transactions on Sustainable Digital Innovation (ITSDI), 1.

20. Amandeep Kaur, R. M. (2018). DIFFERENT TASK SCHEDULING ALGORITHMS IN CLOUD COMPUTING. International Journal of Latest Trends in Engineering and Technology, 9(3), 217-223. doi:http://dx.doi.org/10.21172/1.93.37

21. Anushree B, A. X. V. M. (2018). Comparative Analysis of Latest Task Scheduling Techniques in Cloud Computing environment. Proceedings of the Second International Conference on Computing Methodologies and Communication (ICCMC 2018),IEEE, 608-611.

22. Arghavan Keivani , F. G., Jules-Raymond Tapamo. (2018). A Review of Recent Methods of Task Scheduling in Cloud Computing. IEEE.

23. Ashish Gupta, R. G. (2017). Load Balancing Based Task Scheduling with ACO in Cloud Computing. Paper presented at the International Conference on Computer and Applications.

24. C. Thirumalaiselvan, V. V. (2017). A strategic performance of virtual task scheduling in multi cloud

25. environment. Springer Science+Business Media, LLC. doi:10.1007/s10586-017-1268-7

26. Christian Baun, M. K., Jens Nimis and Stefan Tai. (2011). Cloud Computing. Published in the book series: Informatik im Fokus, Copyright Springer-Verlag Berlin Heidelberg.

27. D.I. George Amalarethinam, S. K. (2017). Priority based Performance Improved Algorithm for Meta-task Scheduling in Cloud Environment. Paper presented at the Second International Conference On Computing and Communications Technologies(ICCCT'17).

28. Danlami Gabi, A. S. I., Anazida Zainal, Zalmiyah Zakaria, Ahmad Al-Khasawneh. (2017). Cloud Scalable Multi-Objective Task Scheduling Algorithm for Cloud Computing Using Cat Swarm Optimization and 
Simulated Annealing. Paper presented at the 8th International Conference on Information Technology (ICIT).

29. Dinkan Patel , A. R. (2018). REVIEW OF TASK SCHEDULING METHODS FOR REAL TIME TASKS IN CLOUD ENVIRONMENT. International Journal of Engineering Technologies and Management Research, 5, 85-89. doi:doi.org/10.29121/ijetmr.v5.i1.2018.50

30. Dino, H. I., Zeebaree, S. R., Ahmad, O. M., Shukur, H. M., Zebari, R. R., \& Haji, L. M. (2020). Impact of Load Sharing on Performance of Distributed Systems Computations. International Journal of Multidisciplinary Research and Publications (IJMRAP), 3(1), 30-37.

31. Fahd Alhaidari, T. B., Eyman AL-Yahyan. (2019). Comparative Analysis for Task Scheduling Algorithms on Cloud Computing. IEEE.

32. Fang Yiqiu, L. X. (2018). Task Scheduling Strategy for Cloud Computing Based on the Improvement of Ant Colony Algorithm. Paper presented at the International Computers, Signals and Systems Conference (ICOMSSC), Dalian, China.

33. Fang Yiqiu, X. X., Ge Junwei. (2019). Cloud Computing Task Scheduling Algorithm Based On Improved Genetic Algorithm. Paper presented at the IEEE 3rd Information Technology,Networking,Electronic and Automation Control Conference (ITNEC 2019).

34. Gibet Tani Hicham, E. A. C. (2016). Cloud Computing CPU Allocation and Scheduling Algorithms

35. Using CloudSim Simulator. International Journal of Electrical and Computer Engineering (IJECE), 6, 1866-1879. doi:0.11591/ijece.v6i4.10144

36. Haji, L. M., Ahmad, O. M., Zeebaree, S. R., Dino, H. I., Zebari, R. R., \& Shukur, H. M. (2020). Impact of cloud computing and internet of things on the future internet. Technology Reports of Kansai University, 62(5), 2179-2190.

37. Haji, L. M., Zeebaree, S., Ahmed, O. M., Sallow, A. B., Jacksi, K., \& Zeabri, R. R. (2020). Dynamic resource allocation for distributed systems and cloud computing. TEST Engineering \& Management, 83, 22417-22426.

38. Hanan M. Shukur, S. R. M. Z., Rizgar R. Zebari, Diyar Qader Zeebaree, Omar M. Ahmed, Azar Abid Salih6. (2020). Cloud Computing Virtualization of Resources Allocation for Distributed Systems. JOURNAL OF APPLIED SCIENCE AND TECHNOLOGY TRENDS, O1, 98-108. doi:doi.org/10.38094/jastt1331

39. Hasan, D. A., Hussan, B. K., Zeebaree, S. R., Ahmed, D. M., Kareem, O. S., \& Sadeeq, M. A. (2021). The Impact of Test Case Generation Methods on the Software Performance: A Review. International Journal of Science and Business, 5(6), 33-44.

40. Hu Yao, X. F., Honghui Li, Gaifang Dong, Jianrong Li. (2017). Cloud Task Scheduling Algorithm based on Improved Genetic Algorithm. International Journal of Performability Engineering, 13, 1070-1076. doi:10.23940/ijpe.17.07.p9.10701076

41. Iqbal, A. H. a. I. (2019). Cloud computing Based Task Scheduling Management Using Task Grouping Balancing. Paper presented at the International Conference on System Engineering and Technology (ICSET), Shah Alam, Malaysia.

42. Jghef, Y. S., \& Zeebaree, S. (2020). State of Art Survey for Significant Relations between Cloud Computing and Distributed Computing. International Journal of Science and Business, 4(12), 53-61.

43. Kadda Beghdad Bey, S. B., Farid Benhammadi,Hassina Nacer. (2019). Improved Virus Optimization algorithm for two-objective tasks Scheduling in Cloud Environment. Paper presented at the Communication Papers of the Federated Conference on Computer Science and Information Systems.

44. Kalka Dubeya, M. K., S.C. Sharma. (2017). Modified HEFT Algorithm for Task Scheduling in Cloud Environment. Paper presented at the 6th International Conference on Smart Computing and Communication, ICSCC 2017, Kurukshetra, India.

45. Laffly, D. (2020). Cloud Computing for Environmental Data. published in Great Britain and the United States by ISTE Ltd and John Wiley \& Sons: Inc.

46. Laith Abualigah, A. D. (2020). A novel hybrid antlion optimization algorithm for multi-objective task scheduling problems in cloud computing environments. Published Online, Springer.

47. Manju Arora, V. K., Meenu Dave. (2020). Task Scheduling in Cloud Infrastructure using Optimization Technique Genetic Algorithm. IEEE.

48. Mehran Ashouraei, S. N. K., Rachid Benlamri, Nima Jafari Navimipour. (2018). new SLA-aware Load Balancing Method in the Cloud using an Improved Parallel Task Scheduling Algorithm. Paper presented at the 6th International Conference on Future Internet of Things and Cloud. 
49. Mohammed, C. M., \& Zebaree, S. R. (2021). Sufficient Comparison Among Cloud Computing Services: IaaS, PaaS, and SaaS: A Review. International Journal of Science and Business, 5(2), 17-30.

50. N. GOBALAKRISHNAN, A. C. A. (2018). A New Multi-Objective Optimal Programming Model for Task Scheduling using Genetic Gray Wolf Optimization in Cloud Computing. COMPUTER AND COMMUNICATIONS NETWORKS AND SYSTEMS THE COMPUTER JOURNAL, 1-14.

51. Negar Chitgar, H. J., Milad Rabiei. (2019). Improving Cloud Computing Performance Using Task Scheduling Method Based on VMs Grouping. Paper presented at the 27th Iranian Conference on Electrical Engineering (ICEE2019), Iran.

52. Nora Almezeini, A. H. (2018). Review on Scheduling in Cloud Computing. IJCSNS International Journal of Computer Science and Network Security, 18, 108-111.

53. Omar M. Ahmed, L. M. H., Hanan M. Shukur, Rizgar R. Zebari, Shakir M. Abas, Mohammad A. M. Sadeeq. (2020). Comparison Among Cloud Technologies and Cloud Performance. JOURNAL OF APPLIED SCIENCE AND TECHNOLOGY TRENDS, 1, 40-47. doi:10.38094/jastt1219

54. Ping Zhu, J. C. a. Y.-G. F. (2019). A power-aware scheduling algorithm for real-time workflow applications in clouds. IEEE, 1870-1873.

55. Pradeep Krishnadoss, P. J. (2018). OCSA: Task Scheduling Algorithm in Cloud Computing Environment. International Journal of Intelligent Engineering and Systems, 11, 271-279. doi:10.22266/ijies2018.0630.29

56. Pratisha Sarma, I. C., Anju Bala. (2017). A Survey on Various Scheduling Techniques in Cloud Computing. International Journal of Recent Trends in Engineering \& Research (IJRTER), 3(7), 303-311.

57. Raja Masadeh, A. S., Basel A. Mahafzah. (2019). Humpback Whale Optimization Algorithm Based on Vocal Behavior for Task Scheduling in Cloud Computing. International Journal of Advanced Science and Technology, 13(3), 121-140.

58. Ram Shringar Rao, N. S., Omprakash Kaiwartya, Sanjoy Das. (2021). Cloud-Based Big Data Analytics in Vehicular Ad-Hoc Networks: Published in the United States of America by IGI Global.

59. Rashid, Z. N., Zebari, S. R., Sharif, K. H., \& Jacksi, K. (2018). Distributed cloud computing and distributed parallel computing: A review. Paper presented at the 2018 International Conference on Advanced Science and Engineering (ICOASE).

60. Rashid, Z. N., Zeebaree, S. R., \& Sengur, A. Novel Remote Parallel Processing Code-Breaker System via Cloud Computing.

61. Rashid, Z. N., Zeebaree, S. R., \& Shengul, A. (2019). Design and analysis of proposed remote controlling distributed parallel computing system over the cloud. Paper presented at the 2019 International Conference on Advanced Science and Engineering (ICOASE).

62. Ruonan Lin, Q. L. (2016). Task Scheduling Algorithm Based on Pre-Allocation Strategy in Cloud Computing. Paper presented at the International Conference on Cloud Computing and Big Data Analysis.

63. Sadeeq, M., Abdulla, A. I., Abdulraheem, A. S., \& Ageed, Z. S. (2020). Impact of Electronic Commerce on Enterprise Business. Technol. Rep. Kansai Univ, 62(5), 2365-2378.

64. Sadeeq, M. A., Zeebaree, S. R., Qashi, R., Ahmed, S. H., \& Jacksi, K. (2018). Internet of Things security: a survey. Paper presented at the 2018 International Conference on Advanced Science and Engineering (ICOASE).

65. Sadeeq, M. M., Abdulkareem, N. M., Zeebaree, S. R., Ahmed, D. M., Sami, A. S., \& Zebari, R. R. (2021). IoT and Cloud Computing Issues, Challenges and Opportunities: A Review. Qubahan Academic Journal, l(2), 1-7.

66. Safwat A. Hamad, F. A. O. (2016). Genetic-Based Task Scheduling Algorithm in Cloud Computing Environment. IJACSA) International Journal of Advanced Computer Science and Applications, 7, 550-556.

67. Salih, A. A., Zeebaree, S. R., Abdulraheem, A. S., Zebari, R. R., Sadeeq, M. A., \& Ahmed, O. M. (2020). Evolution of Mobile Wireless Communication to 5G Revolution. Technology Reports of Kansai University, 62(5), 2139-2151.

68. Sallow, A. B., Sadeeq, M., Zebari, R. R., Abdulrazzaq, M. B., Mahmood, M. R., Shukur, H. M., et al. An Investigation for Mobile Malware Behavioral and Detection Techniques Based on Android Platform. IOSR Journal of Computer Engineering (IOSR-JCE), 22(4), 14-20.

69. Sallow, A. B., Zeebaree, S. R., Zebari, R. R., Mahmood, M. R., Abdulrazzaq, M. B., \& Sadeeq, M. A. Vaccine Tracker/SMS Reminder System: Design and Implementation.

70. Sanaj M S, J. P. P. M. (2020). An Enhanced Round Robin (ERR) algorithm for Effective and Efficient Task Scheduling in cloud environment. IEEE. 
71. SHANCHEN PANG, W. L., HUA HE, ZHIGUANG SHAN, XUN WANG (2019). An EDA-GA Hybrid Algorithm for Multi-Objective Task Scheduling in Cloud Computing. IEEE Access, 7, 146379-146389. doi:0.1109/ACCESS.2019.2946216

72. Sharif, K. H., Zeebaree, S. R., Haji, L. M., \& Zebari, R. R. (2020). Performance Measurement of Processes and Threads Controlling, Tracking and Monitoring Based on Shared-Memory Parallel Processing Approach. Paper presented at the 2020 3rd International Conference on Engineering Technology and its Applications (IICETA).

73. Shengmei Liu, Y. Y. (2019). Task scheduling in Cloud Computing Based on Improved Discrete Particle Swarm Optimization. Paper presented at the IEEE 2nd International Conference on Information Systems and Computer Aided Education (ICISCAE), Dalian, China.

74. Shuang YIN, P. K., Ling TAO. (2018). An improved genetic algorithm for task scheduling in cloud computing. Paper presented at the 13th IEEE Conference on Industrial Electronics and Applications (ICIEA).

75. Shukur, H., Zeebaree, S., Zebari, R., Ahmed, O., Haji, L., \& Abdulqader, D. (2020). Cache coherence protocols in distributed systems. JOURNAL OF APPLIED SCIENCE AND TECHNOLOGY TRENDS, 1(3), 92-97.

76. Shukur, H., Zeebaree, S., Zebari, R., Zeebaree, D., Ahmed, O., \& Salih, A. (2020). Cloud computing virtualization of resources allocation for distributed systems. JOURNAL OF APPLIED SCIENCE AND TECHNOLOGY TRENDS, 1(3), 98-105.

77. Shukur, H., Zeebaree, S. R., Ahmed, A. J., Zebari, R. R., Ahmed, O., Tahir, B. S. A., et al. (2020). A State of Art Survey for Concurrent Computation and Clustering of Parallel Computing for Distributed Systems. JOURNAL OF APPLIED SCIENCE AND TECHNOLOGY TRENDS, 1(4), 148-154.

78. Sidhu, J. K. a. B. K. (2017). New Flower Pollination based Task Scheduling Algorithm in Cloud Environment. Paper presented at the 4th International Conference on Signal Processing, Computing and Control, Solan, India.

79. Sulaiman, M. A., Sadeeq, M., Abdulraheem, A. S., \& Abdulla, A. I. (2020). Analyzation Study for Gamification Examination Fields. Technol. Rep. Kansai Univ, 62(5), 2319-2328.

80. Vijayalakshmi A. Lepaksh, P. C. S. R. (2020). Efficient Resource Allocation with Score for Reliable Task Scheduling in Cloud Computing Systems. Paper presented at the Proceedings of the Second International Conference on Innovative Mechanisms for Industry Applications (ICIMIA 2020).

81. Waleed Abd Elkhalik, A. S., Ibrahim El-Henawy. (2018). A Survey on Cloud Computing Scheduling Algorithms. International Journal of Engineering Trends and Technology (IJETT), 60(1), 65-70.

82. WANG Bei, L. J. (2016). Load Balancing Task Scheduling based on Multi-Population Genetic Algorithm in Cloud Computing. Paper presented at the Proceedings of the 35th Chinese Control Conference, Chengdu, China.

83. Xiaozhong Geng, L. Y., Jie Bao, and Geji Fu (2019). A task scheduling algorithm based on priority list and task duplication in cloud computing environment. Web Intelligence, 121-129. doi:10.3233/WEB-190406

84. Xing Jia Wei, W. B., Li Jun. (2017). SAMPGA Task Scheduling Algorithm in Cloud Computing. Paper presented at the Proceedings of the 36th Chinese Control Conference, Dalian, China.

85. Yanyue Yu, Y. S. (2019). Cloud Task Scheduling Algorithm Based on Three Queues and Dynamic Priority. Paper presented at the International Conference on Power, Intelligent Computing and Systems (ICPICS), Shenyang, China.

86. Yazdeen, A. A., Zeebaree, S. R., Sadeeq, M. M., Kak, S. F., Ahmed, O. M., \& Zebari, R. R. (2021). FPGA Implementations for Data Encryption and Decryption via Concurrent and Parallel Computation: A Review. Qubahan Academic Journal, 1(2), 8-16.

87. Yogesh Hole et al 2019 J. Phys.: Conf. Ser. 1362012121

88. Yong Shi, K. S., Steven Kemp and Jameson Hodge. (2020). A Task Scheduling Approach for Cloud Resource Management. Paper presented at the Fourth World Conference on Smart Trends in Systems, Security and Sustainability (WorldS4).

89. Zebari, S. R., \& Yaseen, N. O. (2011). Effects of Parallel Processing Implementation on Balanced LoadDivision Depending on Distributed Memory Systems. J. Univ. Anbar Pure Sci, 5(3), 50-56.

90. Zeebaree, S., Haji, L. M., Rashid, I., Zebari, R. R., Ahmed, O. M., Jacksi, K., et al. (2020). Multicomputer Multicore System Influence on Maximum Multi-Processes Execution Time. TEST Engineering \& Management, 83(03), 14921-14931.

91. Zeebaree, S., \& Jacksi, K. (2015). Effects of Processes Forcing on CPU and Total Execution-Time Using Multiprocessor Shared Memory System. Int. J. Comput. Eng. Res. Trends, 2(4), 275-279. 
A. H. Radie, Hanan M. Shukur, Mohammed A. M.Sadeeq, Karwan Jacksi, Zryan Najat Rashid Hajar Maseeh Yasin, Subhi R. M. Zeebaree, Ibrahim Mahmood Ibrahim

92. Zeebaree, S. R., Shukur, H. M., Haji, L. M., Zebari, R. R., Jacksi, K., \& Abas, S. M. (2020). Characteristics and analysis of hadoop distributed systems. Technology Reports of Kansai University, 62(4), 1555-1564.

93. Zhen Du, Z. X., Fang Dong, Dian Shen. (2017). A Novel Solution of Cloud Operating System based

94. on X11 and Docker. Paper presented at the Fifth International Conference on Advanced Cloud and Big Data.

95. Zhifeng Zhong, K. C., Xiaojun Zhai, Shuange Zhou. (2016). Virtual Machine-Based Task Scheduling Algorithm in a Cloud Computing Environment. TSINGHUA SCIENCE AND TECHNOLOGY, 21, 660-667.

96. Zong, Z. (2020). An Improvement of Task Scheduling Algorithms for Green Cloud Computing. Paper presented at the The 15th International Conference on Computer Science \& Education (ICCSE 2020). 